\title{
Environmental Degradation and Durability of Epoxy-Clay Nanocomposites
}

\author{
Raman P. Singh, ${ }^{1}$ Mikhail Khait, ${ }^{2}$ Suraj C. Zunjarrao, ${ }^{1}$ Chad S. Korach, ${ }^{2}$ \\ and Gajendra Pandey ${ }^{1}$
${ }^{1}$ Mechanics of Advanced Materials Laboratory, School of Mechanical and Aerospace Engineering, Oklahoma State University, 218 Helmerich Research Center, 700 N. Greenwood Avenue, Tulsa, OK 74106-0700, USA
${ }^{2}$ Laboratory for Nanotribology and Wear Mechanics, Department of Mechanical Engineering, State University of New York, 131 Light Engineering, Stony Brook, NY 11794-2300, USA

Correspondence should be addressed to Raman P. Singh, raman.singh@okstate.edu

Received 17 December 2009; Accepted 2 June 2010

Academic Editor: Gaurav Mago

Copyright ( $) 2010$ Raman P. Singh et al. This is an open access article distributed under the Creative Commons Attribution License, which permits unrestricted use, distribution, and reproduction in any medium, provided the original work is properly cited.

This experimental investigation reports on the durability of epoxy-clay nanocomposites upon exposure to multiple environments. Nanocomposites are fabricated by mixing the clay particles using various combinations of mechanical mixing, high-shear dispersion, and ultrasonication. Clay morphology is characterized using X-ray diffraction and transmission electron microscopy. Specimens of both neat epoxy and the epoxy-clay nanocomposite are subjected to two environmental conditions: combined UV radiation and condensation on 3-hour repeat cycle and constant temperature-humidity, for a total exposure duration of 4770 hours. The presence of nanoscale clay inhibits moisture uptake, as demonstrated by exposure to constant temperature-humidity. Nonetheless, both materials lose mass under exposure to combined UV radiation and condensation due to the erosion of epoxy by a synergistic process. Surprisingly, the epoxy-clay specimens exhibit greater mass loss, as compared to neat epoxy. Mechanical testing shows that either environment does not significant affect the flexure modulus of either material. On the other hand, both materials undergo degradation in flexural strength when exposed to either environment. However, the epoxy-clay nanocomposite retains 37\% more flexure strength than the neat epoxy after 4072 hours of exposure.

\section{Introduction}

Epoxy-based thermosetting polymer resins have received great attention for aerospace and automotive applications due to their superior thermal and mechanical properties such as high modulus, high creep resistance, high glass transition temperature, low shrinkage at elevated temperature, and good resistance to chemicals. These properties have motivated the use of these resins as the matrix in fiber-reinforced composites that are currently being used extensively in aerospace and automotive industries. Such composites have also found applications in infrastructure applications such as bridges, buildings, tranport pipelines, and off-shore drilling platforms due to their superior and directional dependent properties. Despite their inherent advantages, however, such composites are susceptible to environmental conditions, primarily due to the degradation of the epoxy matrix. Hence, there are concerns regarding their overall long-term durability, especially as related to the capacity for sustained performance under harsh and changing environmental conditions.

The fiber reinforced composites used in infrastructure applications undergo mechanical and thermal loading while being exposed to adverse environments including ultraviolet (UV) radiation, moisture (relative humidity), water vapor condensation, and alkaline/salt environment [1]. The properties of the composites degrade when subjected to these harsh environments. Compared to other environments, UV radiation and water vapor are considered to be predominantly responsible for degradation during outdoor service [2]. Since most polymers have bond dissociation energy in the range of the wavelength of UV radiation (290-400 nm), 
they get affected greatly by exposure to the solar spectrum. Ultraviolet photons absorbed by polymers result in photooxidative reactions that alter the chemical structure by molecular chain scission or chain crosslinking that results in material deterioration [3]. Chain scission lowers the molecular weight of the polymer, giving rise to reduced strength and heat resistance; chain crosslinking leads to excessive brittleness and can result in microcracking. For prolonged exposure to UV radiation, the matrix dominated properties, such as interlaminar shear strength, flexural strength, and flexural stiffness can suffer severe deterioration [2, 4-7]. Moisture diffusion into the epoxy matrix on the other hand leads to plasticization and hydrolysis, which can cause both reversible and irreversible changes in thermophysical, mechanical, and chemical characteristics [1,7-9]. Both these processes lower the modulus, glass transition temperature and other matrix-dominated properties such as compressive strength, interlaminar shear strength; fatigue and impact tolerance can also deteriorate [1,9-14]. Plasticization is usually reversible upon desorption of moisture, while hydrolysis of chemical bonds results in permanent irreversible damage. At the same time, moisture wicking along the fiber-matrix interface can degrade the fiber-matrix bond, resulting in loss of microstructural integrity. Furthermore, degradation phenomena due to UV radiation and moisture when acting together can significantly accelerate the degradation process of the matrix. Kumar et al. [6] studied the combined effect of UV and water vapor condensation and found that cyclic exposure leads to a synergistic degradation mechanism causing extensive matrix erosion and resulting loss of mechanical properties.

The reinforcement of polymers with nanoscale fillers offers the potential for significantly enhanced mechanical [15], thermal, and barrier properties [16]. In these nanocomposites, the enhancement in properties is directly related to the surface area of the reinforcement [17]. For a given volume fraction, the surface area of these nanoscale fillers is much higher as compared to that of micron-sized fillers. As a result, significant enhancement in various properties can be observed using very low volume fractions of nanoscale fillers. Among the various nano-sized reinforcements, high-aspect ratio layered silicates (nano-clay) are especially attractive for enhancing the barrier properties and hence the resistance to environmental degradation. Furthermore, nano-clays are readily available, are cheaper than other nanoscale fillers, and have well understood intercalation chemistry [1719]. Polymer-clay nanocomposites can exhibit markedly improved mechanical, thermal, and physicochemical properties, as first demonstrated by Toyota researchers in the early 1990s [20]. Motivated by these studies, many researchers have synthesized and studied the properties of various clayfilled thermoplastic resins such as polyamides, polyimides, polyethylene, poly(methyl methacrylate), and ethylene vinyl acetate copolymers. Alexandre and Dubois [21] provide a summary of different polymers and fabrication routes available in the literature. The focus on polymer-clay nanocomposites based on thermosetting resins, especially epoxy, is more recent [18, 22-24].
In comparison to spherical or fiber-like reinforcement the addition of nanoscale clay reinforcement more effectively enhances the barrier properties such as resistance to helium permeability [25] and resistance to moisture transport [26-29]. Kim et al. [29] found that the appropriate choice of organically modified clay can reduce the moisture permeability by as much as $80 \%$ for clay loading of only 4 wt.\%. Furthermore, Kim et al. observe much higher glass transition temperature for the nanocomposites than the neat epoxy under both dry and wet conditions. These results indicate that reduced moisture permeability could then lead to enhanced environmental resistance and that hypothesis motivates this investigation.

The focus of this paper is on the characterization of the environmental degradation of epoxy-clay nanocomposite under cyclic exposure to both ultraviolet radiation and water vapor condensation. In the past, our studies have shown that these two environments operate in a synergistic manner that leads to extensive degradation by the erosion of the epoxy matrix [6]. It is expected that the addition of clay could mitigate this mechanism by offering a barrier to moisture transport. Furthermore, for the mixing of clay particles in epoxy, prolonged mechanical mixing in association with high-shear dispersion or ultrasonication was investigated following another previous study [24]. The effect of these mixing techniques on the clay morphology and in turn on mechanical properties of epoxy-clay nanocomposites is also investigated.

\section{Experimental Methods}

2.1. Material Fabrication. A commercially available octadecyl ammonium ion modified montmorillonite (MMT) layered silicate (Nanomer I.30E, Nanocor Inc., Arlington Heights, Illinois, USA) was used as the reinforcing agent. The epoxy resin used was Epon 862 (Shell Chemicals, USA) which is a diglycidyl ether of bisphenol $\mathrm{F}$, and the curing agent used was Epikure 3274 (Shell Chemicals, USA) which is a moderately reactive, low viscosity aliphatic amine curing agent. A mechanical mixer (Model 350 Lab Stirrer, Arrow Engineering, Hillside, New Jersey, USA), a high speed shear dispenser (SV $25 \mathrm{KV}-25 \mathrm{~F}$ dispersing element, IKA Works Inc., Wilmington, North Carolina, USA), and an ultrasonic agitator (Model TSX750, Tekmar Dohrmann, Mason, Ohio, USA) were used to mix the clay in epoxy resin in five different ways.

Two different set of samples were fabricated in order to first establish the mixing process by enhancing the mechanical properties, then characterizing the environmental durability of the epoxy-clay nanocomposite. In the first set of samples $2 \%$ clay by volume fraction was used, and the mechanical properties of the different nanocomposite fabricated by using different mixing techniques were compared. To maximize the barrier properties due to addition of clay, it is desired to maximize the volume fraction of the same in the epoxy resin. Previous work by Zunjarrao et al. has shown that no agglomeration-induced deterioration of mechanical properties occurs as the volume fraction of clay 
is increased up to $4 \%$ [24]. Therefore, 4 vol. $\%$ clay was used to fabricate epoxy-clay nanocomposite by using the effecting mixing technique that was established before to evaluate the environmental durability of the nanocomposite. Note that, mechanical property enhancement, especially fracture toughness, is directly correlated to exfoliation and dispersion of clay in the epoxy matrix. The greater the exfoliation, the more the enhancement in barrier properties, and thus, greater resistance to environmental degradation.

The first set of epoxy-clay nanocomposite fabrication started with the addition of $2 \%$ clay by volume fraction to liquid epoxy resin preheated to a temperature of $60^{\circ} \mathrm{C}$. The clay was then dispersed in epoxy by five different ways generating five nanocomposites with same constituents but formed by different processing techniques. In the first and second cases clay was dispersed by simply ultrasonication or high-shear dispersion, respectively, both for a period of 30 minutes. Both these processes led to heat generation due to viscous mixing. Since high temperatures can have a deleterious affect on the epoxy resin used, the temperature of the mixture was maintained at $60-65^{\circ} \mathrm{C}$ by using an ice bath. In the third case, clay was dispersed by stirring the mixture using a mechanical stirrer for a period of 14 hours. While in the fourth and fifth cases, the epoxy-clay mixture was first mixed for 14 hours using a mechanical stirrer and then further mixed using ultrasonication and high-shear dispersion, respectively, both again for 30 minutes. All the five mixtures were further processed and subjected to in situ polymerization using the same procedure. Mixture of clay and epoxy was degassed in a vacuum chamber for 12 hours to completely remove trapped air. A stoichiometric amount of the curing agent was added and hand mixed gently to avoid introduction of any air bubbles due to mixing action. The final slurry, free of air bubbles, was poured into an aluminium mold and allowed to cure under room temperature for 24 hours followed by postcuring at $121^{\circ} \mathrm{C}$ for 6 hours. Specimens for fracture toughness and flexural modulus tests were then cut out of the final cured sheet.

Two types of materials were prepared for environmental durability testing, Neat epoxy samples were prepared as before using Epon 862 and Epikure 3274 mixed with mechanical agitation. The mixed resin was degassed under vacuum for one hour before being poured into a tefloncoated aluminum mold. Curing occurred at $25^{\circ} \mathrm{C}$ for 48 hours followed by postcuring at $121^{\circ} \mathrm{C}$ for 8 hours. The epoxy-clay nanocomposite was fabricated using the previously established procedure that results in optimal dispersion of the nanoclay. First, a desired amount of clay, to result in a final volume fraction of $4 \%$, was added to liquid epoxy resin preheated to $60^{\circ} \mathrm{C}$. This mixture was mixed using a mechanical stirrer for 14 hours while maintaining the temperature at $60^{\circ} \mathrm{C}$ using a hot plate. Subsequently, the mixture was processed for 30 minutes in a high-speed shear dispenser operating at $15,000 \mathrm{rpm}$. The high-shear process produces heat due to frictional dissipation in the polymer, and the temperature of the mixture was maintained at 60 $65^{\circ} \mathrm{C}$ using an ice bath. The mixture was then degassed in a vacuum chamber for 2 hours to completely remove any trapped air. A stoichiometric amount of the curing agent was then added and hand mixed gently to avoid introduction of any air bubbles due to mixing action. The final slurry, free of air bubbles, was poured into a teflon-coated aluminum mold and allowed to cure at $25^{\circ} \mathrm{C}$ for 48 hours followed by postcuring at $121^{\circ} \mathrm{C}$ for 8 hours.

In this manner, three sheets each of neat epoxy and epoxy-clay were fabricated with nominal dimensions of $110 \times 110 \times 3.2 \mathrm{~mm}$. Specimens were then machined out of the fabricated sheets with nominal dimensions of $63.5 \times$ $12.7 \times 3.2 \mathrm{~mm}$ using a water-cooled, high-speed diamond saw. This specimen size was required for the flexure tests to be conducted after environmental exposure. Each sheet yielded fourteen specimens, which lead to a sufficiently large number of samples for generating statistically relevant data. The cured sheets and machined specimens were stored in a dessicator prior to environmental exposure and conditioning.

2.2. Mechanical Properties. Mechanical properties of epoxyclay composites to establish the mixing procedure were characterised in terms of the flexural modulus and critical stress intensity factor.

The flexural moduli of neat epoxy and the epoxy-clay nanocomposites were determined as per ASTM standard D6272-10 [30]. Specimens with a nominal size of $63.5 \times$ $12.7 \times 6.35 \mathrm{~mm}(2.5 \times 0.5 \times 0.25$ in $)$ were quasistatically loaded under four-point bending on a bench-top testing frame (Tira Test 2500, TIRA GmbH, Schalkau, Germany) at a crosshead speed of $1.5 \mathrm{~mm} /$ minute, support span width of $49.6 \mathrm{~mm}$, and a loading span width of $24.8 \mathrm{~mm}$. The load was measured using a $2000 \mathrm{~N}$ load cell, and the load-point specimen displacement was measured using a linear variable displacement transducer (Schaevitz Sensors, Hampton, Virginia, USA). At least four samples were tested for each volume fraction and each material processing technique used.

Fracture tests were carried out on neat epoxy and epoxyclay nanocomposites using single edge notched specimens having a nominal size of $55.8 \times 12.7 \times 6.35 \mathrm{~mm}(2.2 \times 0.5 \times 0.25$ in). Specimens were quasistatically loaded under three-point bending on the bench-top testing frame. In order to generate a starter crack, first a $4.8 \mathrm{~mm}$ deep notch was machined into the specimen using a high-speed diamond saw (MK-370, MK Diamond Products Inc., Torrance, CA). Subsequently, a razor blade was inserted into this machined notch and tapped with a small load using a jig designed in-house to generate a small, yet well-controlled starter precrack. The peak load, as obtained from the load-displacement curve, was used as the maximum applied force, $P$, to determine the fracture toughness.

Precise measurement of the actual crack length, $a$, was done after the fracture experiments using an optical microscope equipped with a micrometer stage. All specimens considered valid for fracture tests had a nominal crack length to specimen width ratio, $a / W$, of $0.45-0.5$, as per ASTM standard 5045 [31]. The fracture toughness was calculated using $K_{I c}=P /(B \sqrt{W}) f(a / W)$, where $P$ is the maximum applied force, $B$ is the thickness of specimen, $W$ is width of 
the specimen, and the function $f(a / W)$ is a geometry factor [32].

2.3. Clay Dispersion Morphology. In order to investigate the structure of clay formed in the final composites fabricated for establishing the mixing procedure, wide angle X-ray diffraction (WAXD) measurements were carried out on the epoxy-clay composites using Scintag PAD-X automated diffractometer with a $\mathrm{CuK}_{\alpha}$ radiation $(\lambda=0.1540 \mathrm{~nm})$ and a scanning rate of $0.5^{\circ} \mathrm{C}$ per min. The generator was operated at $45 \mathrm{kV}$ and $25 \mathrm{~mA}$. WAXD measurements were also performed on cured samples of neat epoxy (EPON 862) and pure clay powder (Nanocor I.30E).

The morphology of clay particles was also studied under a transmission electron microscope (TEM). Specimens were cut from nanocomposite blocks using an ultramicrotome. The structure of clay particles in the nanocomposites was observed using a Phillips CM12 TEM at an accelerated voltage of $80 \mathrm{kV}$. Several specimens were cut from each material to investigate the extent of clay exfoliation and the presence of agglomerated particles.

2.4. Environmental Exposure. Neat epoxy and epoxy-clay nanocomposite specimens were subjected to two environmental conditions for characterizing their environmental durability.

2.4.1. Combined UV Radiation and Condensation. The samples were exposed to alternating 3-hour cycles of UV radiation and water vapor condensation at a temperature of $50^{\circ} \mathrm{C}$. The combined environment was simulated on a QUV/se Accelerated Weathering Tester, (Q-Panel Lab Products, Cleveland, Ohio, USA).

2.4.2. Relative Humidity. The samples were exposed to a constant $80 \%$ relative humidity environment at $50^{\circ} \mathrm{C}$ in a temperature-humidity chamber (Benchmaster BTRS, Tenney Environmental, Williamsport, Pennsylvania, USA). From each batch five samples were used for each environmental condition, and four samples were held as control. Various exposure details were employed, and Table 1 lists details of the two environmental exposure conditions.

Throughout the exposure process, samples were removed on a regular basis for mass loss measurements. For the first two weeks the samples were weighed every 24 hours. Afterwards, the samples were weighed every 48 hours and finally every 72 hours. The samples in the QUV chamber were turned over after every weight measurement to ensure even exposure to the UV and condensation on both sides of the specimen. The time required to reach thermal equilibrium for the QUV environmental chamber is $\sim 15-20$ minutes. Therefore, in order to ensure the most accurate weight reading, the samples in the QUV chamber were removed ten minutes prior to the end of the UV cycle. This ensured that the samples were dry and that the temperature within the chamber remained close to $50^{\circ} \mathrm{C}$.
2.5. Post-Degradation Testing. At the end of the environmental exposure, the specimens were tested to determine the flexural modulus and strength as per ASTM standard D627210 [30]. Specimens with a nominal size of $63.5 \times 12.7 \times$ $3.2 \mathrm{~mm}$ were quasistatically loaded under four-point bending on a bench-top testing frame (Model 5567, Instron, Canton, Massachusetts, USA) at a crosshead speed of $13.13 \mathrm{~mm} / \mathrm{min}$, with a support span of $49.6 \mathrm{~mm}$ and a loading span of $24.8 \mathrm{~mm}$. The load was measured using a $30 \mathrm{kN}$ load cell, and the load-point specimen displacement was measured using the crosshead motion. Flexure modulus and strength were studied as an environmental exposure duration for both neat epoxy and the epoxy-clay nanocomposite. At least four specimens were tested for each material, environmental exposure, and exposure duration.

2.6. Postdegradation Surface Degradation. The surface of both neat epoxy and epoxy-clay composite samples was imaged using a high resolution digital microscope (Keyence Digital Microscope VHX 500, Osaka, Japan), as a function of environmental exposure. This camera records multiple images for each location at various focussing depths to create a 3-dimensional reconstruction of the surface. This process produces images that are in sharp focus and also allows for quantitative surface analysis. The imaging was conducted at a magnification power of 500x, which yielded a $610 \mu \mathrm{m} \times$ $457 \mu \mathrm{m}\left(0.279 \mathrm{~mm}^{2}\right)$ viewing area. The camera is capable of an 18 mega pixel resolution. For this study, however, a resolution of 3.2 mega pixels was found to be adequate for both qualitative observations and quantitative image analysis. Up to ten images were taken for each sample, at different locations, to obtain an accurate representation of the surface. Finally, due to the amount of time required to take photographs of each sample, the imaging was done only at the end of each degradation cycle.

\section{Results and Discussion}

3.1. Mechanical Properties. The comparison of flexural modulus values for epoxy-clay nanocomposites prepared in five different ways is shown in Table 2. For comparison purposes the flexural modulus of neat epoxy resin was also determined and is listed in the table. In general, all the nanocomposites showed improved modulus as compared to neat epoxy. Nanocomposites processed using either ultrasonication or high-shear dispersion exhibited higher modulus than processing by just mechanical mixing. Furthermore, nanocomposites processed by combination of mechanical mixing and ultrasonication or high-shear dispersion showed higher modulus than nanocomposites processed by only mechanical mixing and by either ultrasonication or high-shear dispersion alone. It can be seen that highshear dispersion led to higher modulus vis-à-vis ultrasonic mixing. Of all the nanocomposites prepared by the five different mixing methods, the nanocomposites processed by prolonged mechanical mixing followed by high-shear dispersion lead to the greatest improvement in flexural modulus. 
TABLe 1: Details of the environmental exposure conditions.

\begin{tabular}{lcc}
\hline Environment & Exposure condition & Duration \\
\hline \multirow{4}{*}{ Combined UV radiation and condensation } & 3-hour repeated cycle & \\
& $\mathrm{UV}: 0.68 \mathrm{~W} / \mathrm{m}^{2}$ irradiance at $340 \mathrm{~nm}$ & 1320, 2712, and 4098 hours \\
& Condensation: $100 \%$ relative humidity & \\
Moisture & Temperature: $50^{\circ} \mathrm{C}$ & \\
& Continuous exposure & 1320, 2712, and 4098 hours \\
\hline
\end{tabular}

TABLE 2: Initial mass gain and final mass loss for exposure to UV radiation and condensation.

\begin{tabular}{lccc}
\hline Material & Processing & Flexure modulus $(\mathrm{GPa})$ & Fracture toughness $(\mathrm{MPa} \sqrt{\mathrm{m}})$ \\
\hline Neat epoxy & None & $2.70 \pm 0.05$ & $0.94 \pm 0.05$ \\
\hline & Hand mix + ultrasonication & $3.59 \pm 0.11$ & $1.23 \pm 0.07$ \\
Epoxy-clay & Hand mix + high-shear dispersion & $3.69 \pm 0.04$ & $1.31 \pm 0.04$ \\
Nanocomposite & 14 hour mechanical mixing & $3.50 \pm 0.06$ & $1.29 \pm 0.02$ \\
& 14 hours mechanical + ultrasonication & $3.75 \pm 0.10$ & $1.17 \pm 0.03$ \\
& 14 hours mechanical + high-shear dispersion & $3.94 \pm 0.20$ & $1.34 \pm 0.05$ \\
\hline
\end{tabular}

Table 2 also lists the fracture toughness values for epoxyclay nanocomposites prepared in five different ways. Fracture toughness was also determined for plain epoxy samples and is listed for comparison. Unlike flexural modulus, fracture toughness was higher for nanocomposite processed with just prolonged mechanical mixing as compared to that processed by 1 hour mechanical and 30 minutes high-shear dispersion. Nanocomposite processed by just high-shear dispersion exhibited higher fracture toughness than that processed by just mechanical mixing, and nanocomposite processed by combination of 14 hours mechanical and 30 minutes high-shear dispersion exhibited the highest values for fracture toughness of all the nanocomposites studied. However, nanocomposites processed by ultrasonic mixing and combination of mechanical and ultrasonic mixing exhibited lower values for fracture toughness.

The incorporation of extended mechanical mixing contributes significantly to the exfoliation of clay, and the best properties are obtained for extended mechanical mixing followed by high-shear dispersion. In fact the values of modulus and fracture toughness obtained in this study are both higher than properties obtained in an earlier investigation that employed only 1 hour of mechanical mixing. The improved properties of epoxy-clay nanocomposites processed by just high-shear dispersion and combination of prolonged mechanical and high-shear dispersion as compared to just ultrasonication can be attributed to the better dispersion of clay and the greater exfoliation of clay particles, which is indicated by XRD measurements discussed in the following section.

3.2. Morphology. X-ray diffraction studies (XRD) were performed on the epoxy-clay specimens to study the morphology of clay particles in the cured composites. Figure 1 shows the diffractograms obtained for a cured specimen of plain epoxy (a), clay powder (g), and all the epoxy-clay specimens (b)-(f). It can be seen that neat epoxy did not show any peaks in the diffraction pattern, as is expected owing to its amorphous nature. A distinct $2.2 \mathrm{~nm}$ peak can be seen in the diffractogram obtained for composites fabricated by just ultrasonication (b). Also, slight peaks can also be observed for materials processed using just high-shear dispersion (c). These peaks are suggestive of intercalated clay morphology where in the clay platelet separation is not very large. On the other hand, epoxy clay nanocomposites fabricated by 14 hours of just mechanical mixing (d), those fabricated by mechanical mixing followed by ultrasonication (e) and those fabricated by mechanical followed by high-shear dispersion (f), show no peaks, indicating that complete exfoliation of clay is achieved in these composites. Figure 1 also shows diffractogram obtained for pure I.30E clay powder $(\mathrm{g})$ in which characteristic peaks corresponding to (001) and (002) planes can be seen at $2.2 \mathrm{~nm}$ and $1.1 \mathrm{~nm}$, respectively.

Clay morphology was further characterised using transmission electron microscopy (TEM). Figure 2 shows four TEM images obtained from a sample fabricated using 14 hours of mechanical mixing followed by high-shear dispersion. As can be seen from Figures 2(a)-2(c), several regions of the material show the presence of exfoliated clay platelets. Nonetheless, even with this processing technique there were regions that exhibited clay particles that were neither exfoliated nor intercalated, as shown in Figure 2(d).

3.2.1. Mass Loss or Gain upon Environmental Exposure. When exposed to constant relative humidity conditions in the temperature-humidity chamber, both neat epoxy and epoxy-clay composite samples gained mass due to moisture uptake, as can be seen in Figures 3 and 4. These figures show data from multiple samples, to demonstrate scatter, and also plots the averaged variation. A comparison of 
TABle 3: Flexure modulus values in GPa for neat epoxy and epoxy-clay nanocomposites, as a function of exposure duration, subjected to environmental exposure by either temperature-humidity or by combined UV radiation and condensation.

\begin{tabular}{|c|c|c|c|c|}
\hline \multirow{2}{*}{ Exposure duration } & \multicolumn{2}{|c|}{ Temperature-humidity } & \multicolumn{2}{|c|}{ UV and condensation } \\
\hline & Neat epoxy & Epoxy-clay & Neat epoxy & Epoxy-clay \\
\hline 0 & $4.4 \pm 0.3$ & $4.6 \pm 0.2$ & $4.4 \pm 0.3$ & $4.6 \pm 0.2$ \\
\hline 1320 & $4.9 \pm 0.1$ & $4.8 \pm 0.3$ & $4.2 \pm 0.2$ & $5.1 \pm 0.4$ \\
\hline 2712 & $4.8 \pm 0.3$ & $4.9 \pm 0.3$ & $3.7 \pm 0.4$ & $4.5 \pm 0.3$ \\
\hline 4098 & $5.1 \pm 0.2$ & $4.8 \pm 0.2$ & $3.9 \pm 0.2$ & $4.3 \pm 0.2$ \\
\hline
\end{tabular}

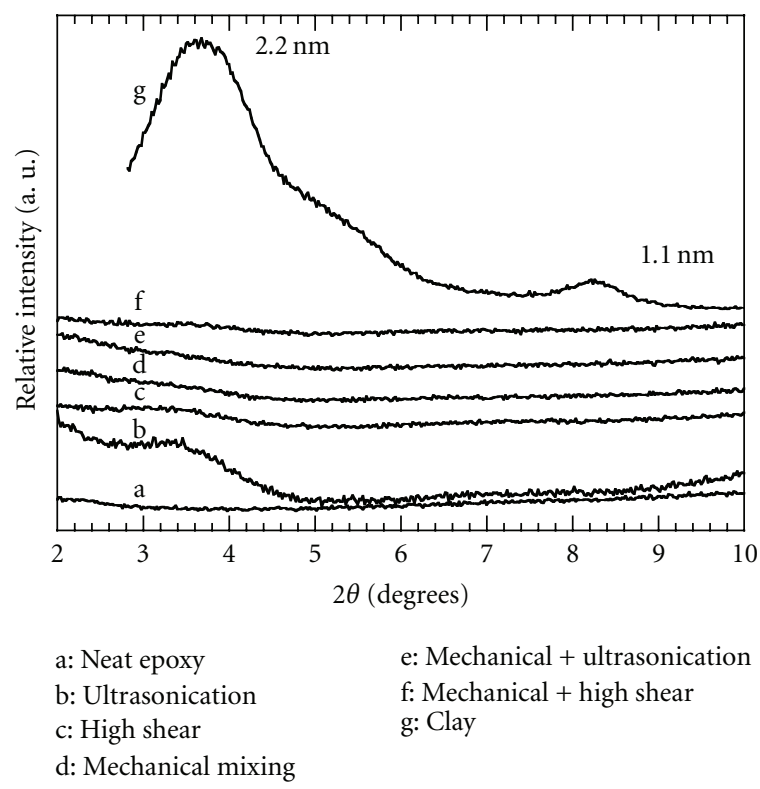

Figure 1: Wide angle X-rad diffraction (WAXD) patterns for epoxy-clay nanocomposites prepared using various processing techniques, along with the reference patterns for neat epoxy and clay powder.

the moisture absorption for neat epoxy and the epoxy-clay nanocomposites is shown in Figure 5 after taking an average reading from all the samples.

Both materials started gaining mass at a similar high rate for the first 250-325 hours and exhibited an increase of $\sim 1.6 \%$. Shortly thereafter, the rate of moisture absorption for the epoxy-clay nanocomposite was minimal. Meanwhile, the neat epoxy specimens continued to increase in mass, and were not approaching saturation even after 4770 hours of exposure. The final mass gain by the epoxy-clay samples was $2.0 \%$ and for neat epoxy was 3.4\%.

The variations in specimen mass for neat epoxy and epoxy-clay nanocomposite specimens exposed to combined UV radiation and condensation are shown in Figures 6 and 7. A comparison of averaged mass loss data for neat epoxy and epoxy-clay nanocomposites exposed to combined UV radiation and condensation is shown in Figure 8. In both cases, the samples gained in mass, for the first 100-500 hours, due to moisture uptake by the epoxy. Subsequently, the specimens started to lose mass by an epoxy erosion process. This process was first demonstrated by Kumar et al. [6], albeit for a different epoxy matrix, and is related to the synergistic physicochemical degradation of epoxy upon exposure to combined UV radiation and condensation.

At the end of the exposure duration, at 4770 hours, the neat epoxy samples had lost $\sim 1.8$ wt. $\%$ while the epoxyclay nanocomposite specimens had lost $2.87 \mathrm{wt} . \%$. It was surprising to note that the epoxy-clay specimens exhibited greater mass loss, as compared to neat epoxy. This could indicate a greater degradation for the latter material due to synergistic erosion of the epoxy matrix. Nevertheless, this is not readily apparent given the moisture uptake results obtained for exposure to a constant relative humidity environment. During the exposure to combined UV radiation and condensation, there are two competing mechanisms that govern the variation of specimen mass: decrease in mass due to loss of epoxy matrix and increase in mass due to moisture absorption. Therefore, the increased mass loss for epoxyclay nanocomposites could indicate either increased erosion of the epoxy matrix or a decreased uptake of moisture. Just based on mass loss or gain measurements it is not possible to identify which mechanism leads to the observed increase in mass loss.

3.2.2. Effect of Environmental Exposure on Residual Properties. Table 3 lists the measured values of flexure modulus, as a function of exposure duration, for neat epoxy and epoxyclay nanocomposites exposed to the two environmental conditions. As shown, exposure to relative humidity does not lead to a significant change in modulus for either material. In fact it appears that the modulus marginally increases due to moisture absorption, however, data scatter (in $\pm 1 \sigma$ ) precludes a concrete observation. For exposure to UV radiation and condensation, the flexure modulus marginally decreases for both materials with increasing exposure duration. This modulus decrease is due to epoxy erosion from synergistic material degradation. The decrease in modulus is slightly greater for the neat epoxy specimens as compared to the epoxy-clay nanocomposite, which indicates that the presence of clay leads to increased environmental durability.

The measured values of flexure strength, as a function of exposure duration, are listed in Table 4. Both materials undergo degradation in strength when exposed to either environment. The decrease in flexural strength is severe especially for the case of exposure to combined UV radiation and condensation. Nevertheless, the decrease is lower for the 


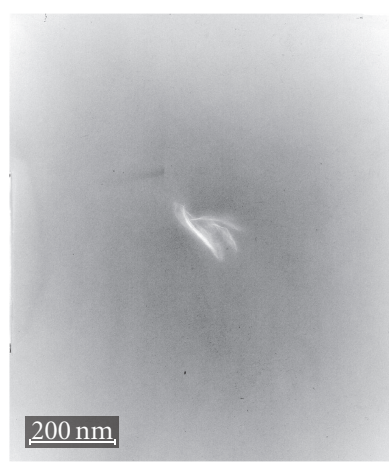

(a)

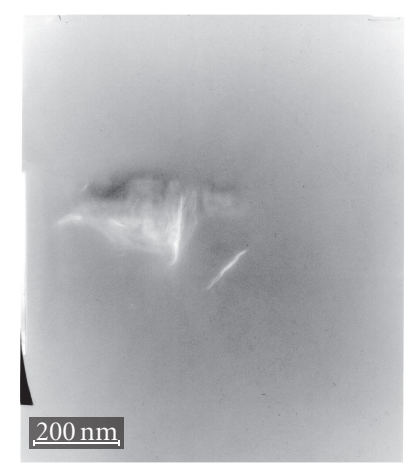

(b)

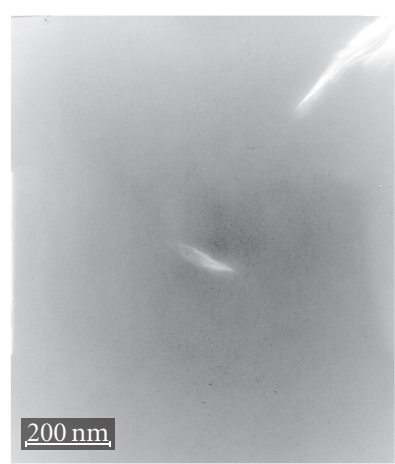

(c)

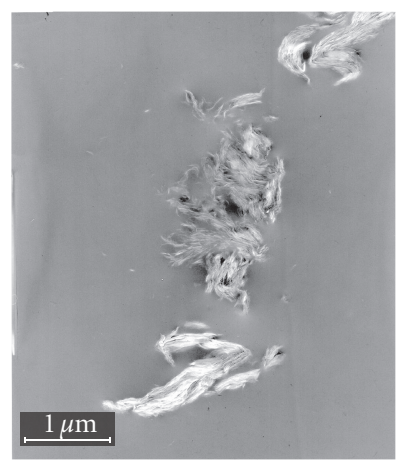

(d)

FIGURE 2: TEM images obtained from different regions of an epoxy-clay nanocomposite sample processed using 14 hours of mechanical mixing followed by high-shear dispersion.

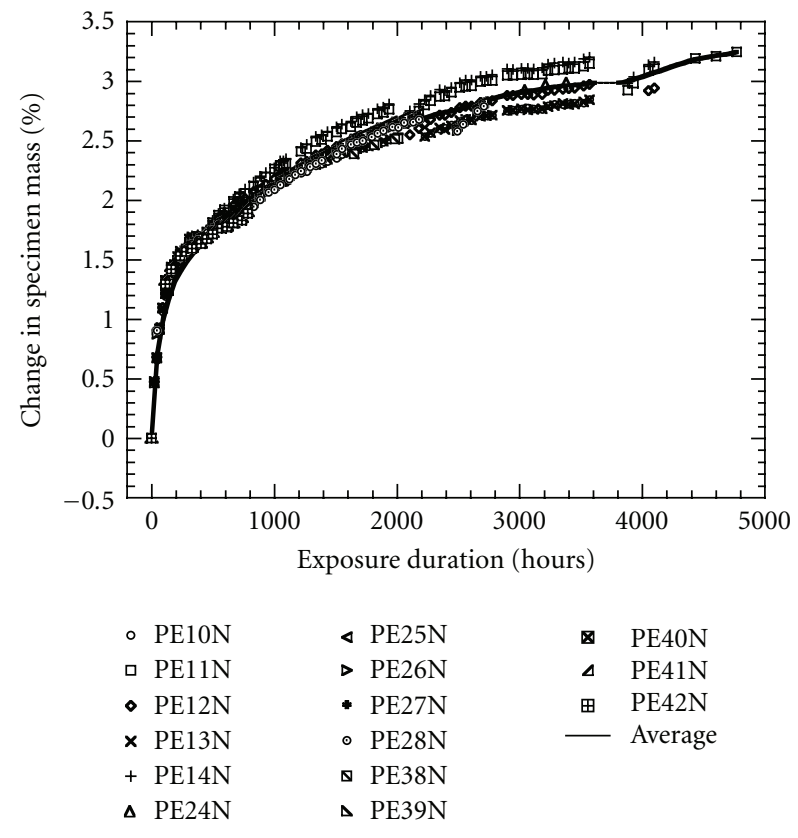

FIGURE 3: Moisture uptake for neat epoxy samples upon exposure to at moisture $80 \%$ relative humidity and $50^{\circ} \mathrm{C}$.

epoxy-clay nanocomposite, again leading to the conclusion that the addition of clay particles leads to enhancement in the resistance to environmental degradation.

Since the as fabricated epoxy-clay nanocomposite specimens have a higher modulus and strength than neat epoxy, the results of flexure strength degradation have been normalized and are listed in Table 5. The flexure strengths for both neat epoxy and epoxy-clay nanocomposite have been normalized by their respective undegraded values. The relative strength listed is for epoxy-clay as compared to neat epoxy for a given exposure duration and environment. As illustrated in this table, the incorporation of nanoscale clay particles leads to enhancement of resistance to environmental degradation for combined UV radiation and condensation, but not for moisture.
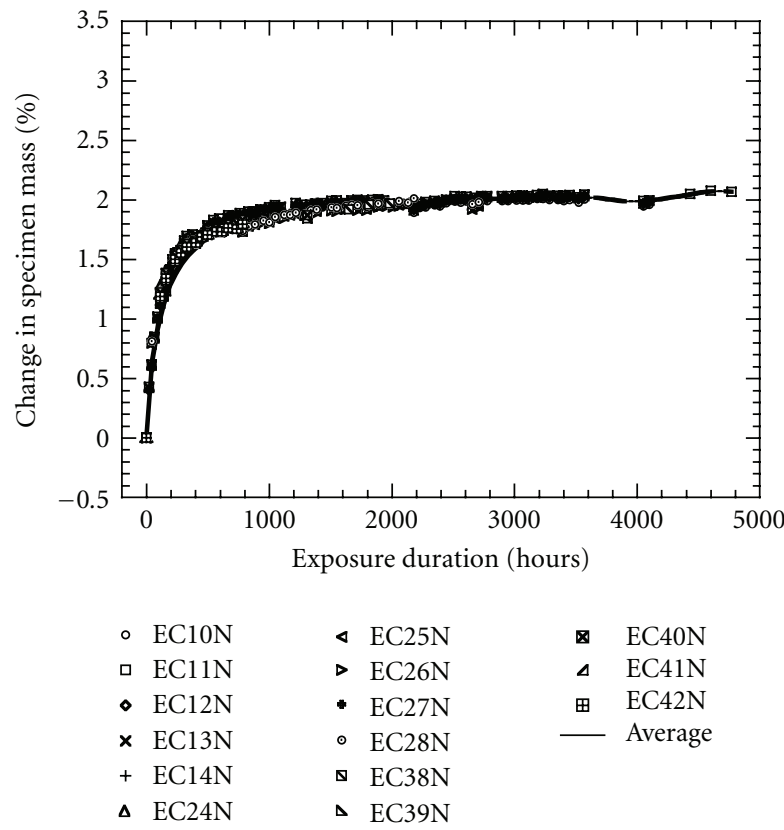

FIGURE 4: Moisture uptake for epoxy-clay composite samples upon exposure to at moisture $80 \%$ relative humidity and $50^{\circ} \mathrm{C}$.

3.3. Environmentally Induced Surface Degradation. Exposure of epoxy resins to UV radiation leads to the formation of microcracks, which can then serve as localized sites for further material degradation, especially when synergistic degradation mechanisms are operative. In this investigation, the surfaces of both neat epoxy and epoxy-clay composite samples were monitored as a function of exposure duration.

Specimens exposed to UV radiation and condensation started exhibiting surface degradation, that was even visible by eye, after approximately two weeks (336 hours) of exposure. With increasing exposure, further degradation of the surface was observed. Initially, small cracks developed close to the surface. As exposure progressed, the cracks became larger in size and increased in quantity. After about 3500 hours of exposure, hemispherical dome-shape dimples 
TABLE 4: Flexure strength values in MPa for neat epoxy and epoxy-clay nanocomposites, as a function of exposure duration, subjected to environmental exposure by either temperature-humidity or by combined UV radiation and condensation.

\begin{tabular}{|c|c|c|c|c|}
\hline \multirow{2}{*}{ Exposure duration } & \multicolumn{2}{|c|}{ Temperature-humidity } & \multicolumn{2}{|c|}{ UV and condensation } \\
\hline & Neat epoxy & Epoxy-clay & Neat epoxy & Epoxy-clay \\
\hline 0 & $99 \pm 8$ & $107 \pm 10$ & $99 \pm 8$ & $107 \pm 10$ \\
\hline 1320 & $76 \pm 33$ & $52 \pm 14$ & $24 \pm 2$ & $33 \pm 4$ \\
\hline 2712 & $61 \pm 16$ & $51 \pm 16$ & $16 \pm 3$ & $27 \pm 3$ \\
\hline 4098 & $51 \pm 18$ & $50 \pm 14$ & $19 \pm 2$ & $29 \pm 4$ \\
\hline
\end{tabular}

TABLE 5: Normalized flexure strength for specimens, as a function of exposure duration.

\begin{tabular}{|c|c|c|c|c|}
\hline \multirow{2}{*}{ Environment } & \multirow{2}{*}{ Exposure duration } & \multicolumn{2}{|c|}{ Normalized Flexure Strength } & \multirow[t]{2}{*}{ Relative strength } \\
\hline & & Neat epoxy & Epoxy-clay & \\
\hline \multirow{4}{*}{ Moisture } & 0 & 1.00 & 1.00 & $0.0 \%$ \\
\hline & 1320 & 0.61 & 0.49 & $-19.4 \%$ \\
\hline & 2712 & 0.62 & 0.49 & $-21.3 \%$ \\
\hline & 4098 & 0.53 & 0.47 & $-12.2 \%$ \\
\hline \multirow{4}{*}{ UV radiation and condensation } & 0 & 1.00 & 1.00 & $0.0 \%$ \\
\hline & 1320 & 0.24 & 0.31 & $29.6 \%$ \\
\hline & 2712 & 0.17 & 0.25 & $47.9 \%$ \\
\hline & 4098 & 0.19 & 0.26 & $37.3 \%$ \\
\hline
\end{tabular}

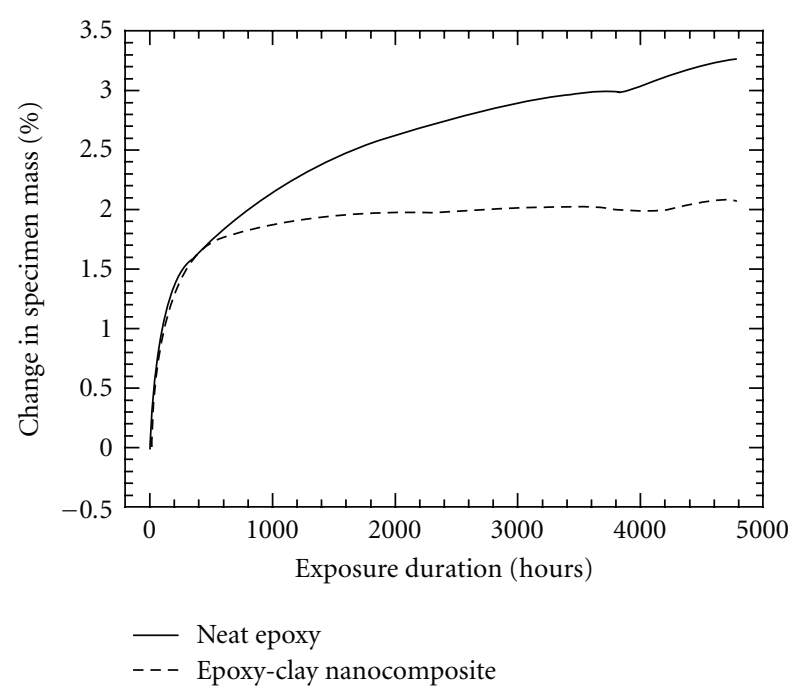

Figure 5: Comparison of average moisture uptake for neat epoxy and epoxy-clay nanocomposite specimens.

were observed on some areas of the surface. The dimples varied in size and were visible to the naked eye. The surface degradation, however, was not uniform throughout the sample. Microcracking was mostly observed near the center of samples, while the dimples developed closer to the edges near the sample holders. Therefore, it is conceivable that microcracking dominated surface changes were due to inherent material degradation, while the dimples were results of physicochemical interaction with the sample holders. Therefore, only the microcracked regions were imaged using

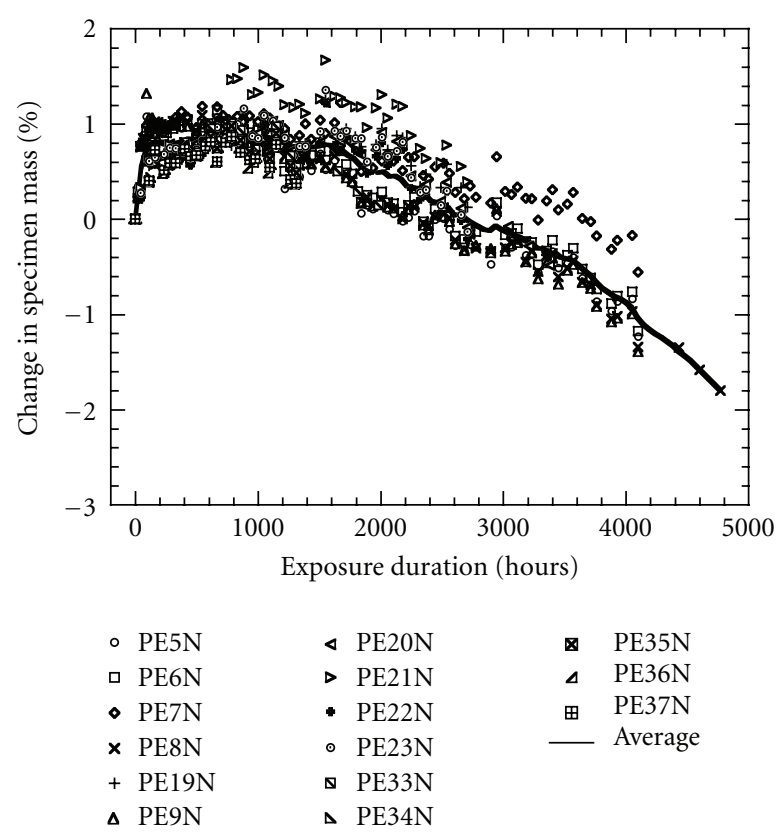

FIGURE 6: Mass variation for neat epoxy specimens upon exposure to combined UV radiation and water vapor condensation.

high-resolution microscopy for further quantitative and qualitative analysis.

Figure 9 shows images for neat epoxy samples taken after 1320, 2712, and 4098 hours of exposure to UV radiation and condensation. These are typical images taken from different specimens at the end of each selected degradation cycle. From these images, it is apparent that the microcracks 
formed by exposure to UV radiation become focus sites for subsequent degradation and erosion upon exposure to cyclic UV radiation and condensation. Previously, Kumar et al. discussed this synergistic degradation mechanism in multienvironment exposure of epoxy. In this case, condensation droplets could get trapped in the microtrenches, leading to more and more erosion in the trench. As a result, degradation proceeds by the microcracks eroding to form trenches (or channels), and then the trenches get bigger and bigger with continued material removal.

A similar set of images obtained for epoxy-clay composite samples is shown in Figure 10. In this case, as for the neat epoxy, material degradation proceeded by erosion of channels initially formed due to UV radiation-induced microcracking. Also, in addition to the increase in size and depth of the trenches (channels), the density of trenches increased as well. This is simply due to the formation of additional microcracks during the UV radiation segments of the cyclic exposure protocol.

From a direct visual comparison of Figures 9 and 10 it is apparent that less material erosion takes place for the epoxy-clay nanocomposites. This indicates that the presence of clay platelets helps in ameliorating material loss due to synergistic material degradation. Figures 11 and 12 show the evolution of trench cross-section profiles, as a function of exposure duration, for the neat epoxy and the epoxyclay composite samples, respectively. Data for both materials has been plotted at the same scale to facilitate comparison. From the figures it is apparent that trench formation in the case of neat epoxy was much more aggressive than for the case of epoxy-clay composites. This again indicates that the presence of clay is significant in slowing down material erosion due to synergistic degradation. It is important to note that Figures 11 and 12 are not representative of the entire surface and are localized areas of degradation; other locations on the same sample would yield different crack depths and widths. Nonetheless, these figures illustrate the quantitative difference in trench formation for the two materials.

The 3-dimensional imaging data was also used to determine the changes in volume and surface area for the two materials. The microscope cannot directly provide the actual change in volume due to material degradation. Instead, it provides a measurement of the current volume of the remaining material. This data was used to calculate the relative change in material volume, as a function of exposure duration. The change in material volume, normalized with respect to the viewing area of the Keyence microscope, is plotted in Figure 13. The average rate of volume change for the neat epoxy materials was $\sim 6.4 \times 10^{-3} \mu \mathrm{m}^{3} / \mu \mathrm{m}^{2}$ per unit area per hour, while that for the epoxy-clay nanocomposite was nearly half at $\sim 3.4 \times 10^{-3} \mu \mathrm{m}^{3} / \mu \mathrm{m}^{2}$ per unit area per hour. Also, for the durations considered, the change in material volume continues to increase. This implies that material erosion will continue to occur because of synergistic degradation.

The imaging data can also be used to determine the change in material surface area. Figure 14 plots the change in material surface area, normalized with respect to the viewing

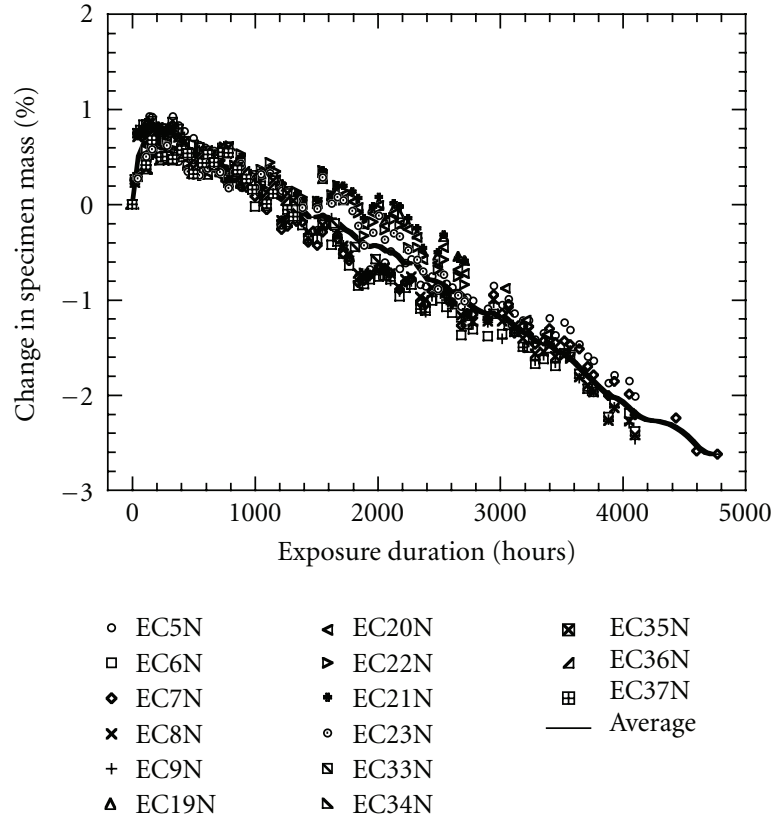

FIGURE 7: Mass variation for epoxy-clay nanocomposite specimens upon exposure to combined UV radiation and water vapor condensation.

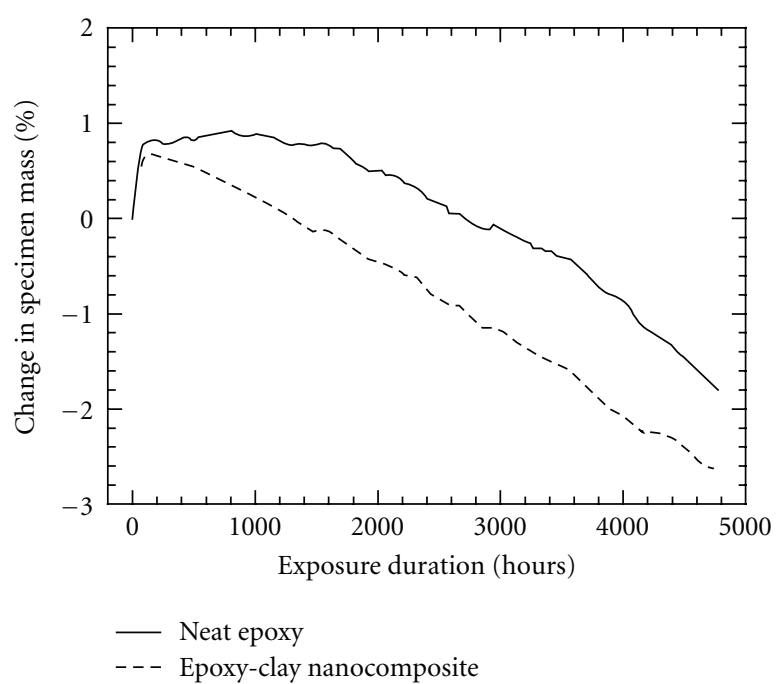

FIGURE 8: Comparison of mass variation for neat epoxy and epoxyclay nanocomposite specimens upon exposure to combined UV radiation and water vapor condensation.

area, for neat epoxy and epoxy-clay composites, as a function of exposure duration. The average rate of surface change for the neat epoxy materials was $\sim 3.8 \times 10^{-5} \mu \mathrm{m}^{2} / \mu \mathrm{m}^{2}$ per unit area per hour, while that for the epoxy-clay nanocomposite was nearly half at $\sim 1.5 \times 10^{-5} \mu \mathrm{m}^{2} / \mu \mathrm{m}^{2}$ per unit area per hour. As for the material volume change, the surface change continues to increase for the durations considered. 


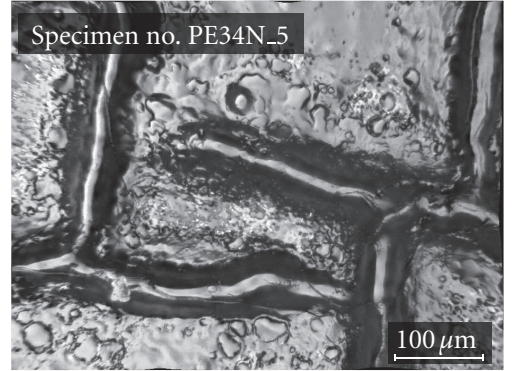

(a) 1320 hours of exposure

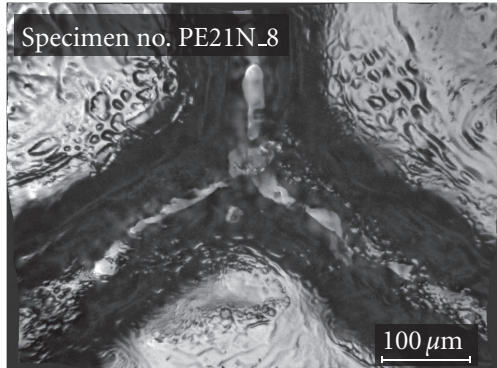

(b) 2712 hours of exposure

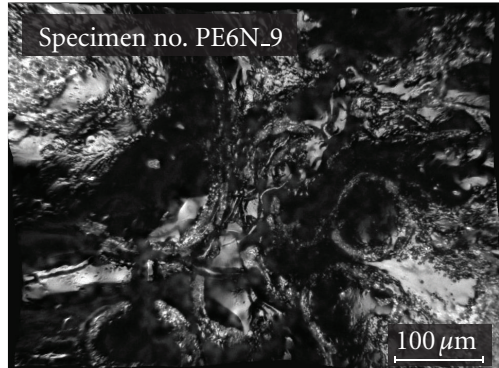

(c) 4098 hours of exposure

FIGURE 9: Images of neat epoxy specimens after exposure to UV radiation and condensation showing progressive erosion of microcracks.

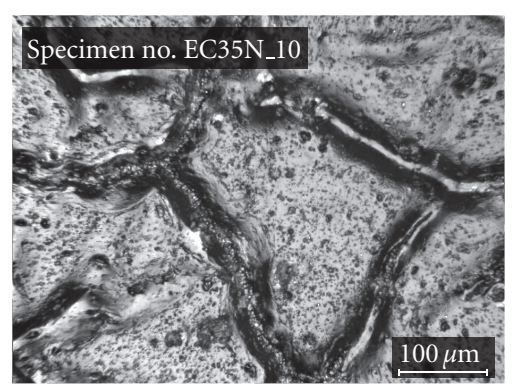

(a) 1320 hours of exposure

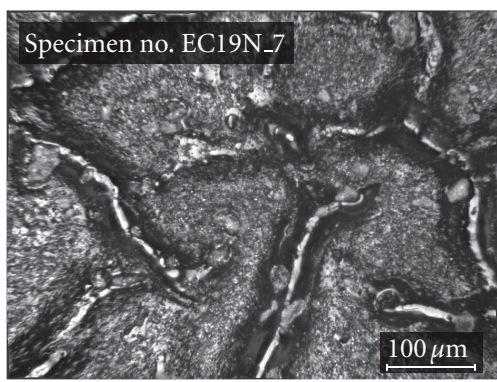

(b) 2712 hours of exposure

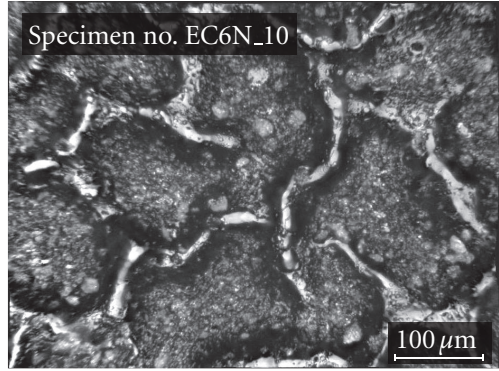

(c) 4098 hours of exposure

FIGURE 10: Images of epoxy-clay composites after exposure to UV radiation and condensation showing progressive erosion of microcracks.

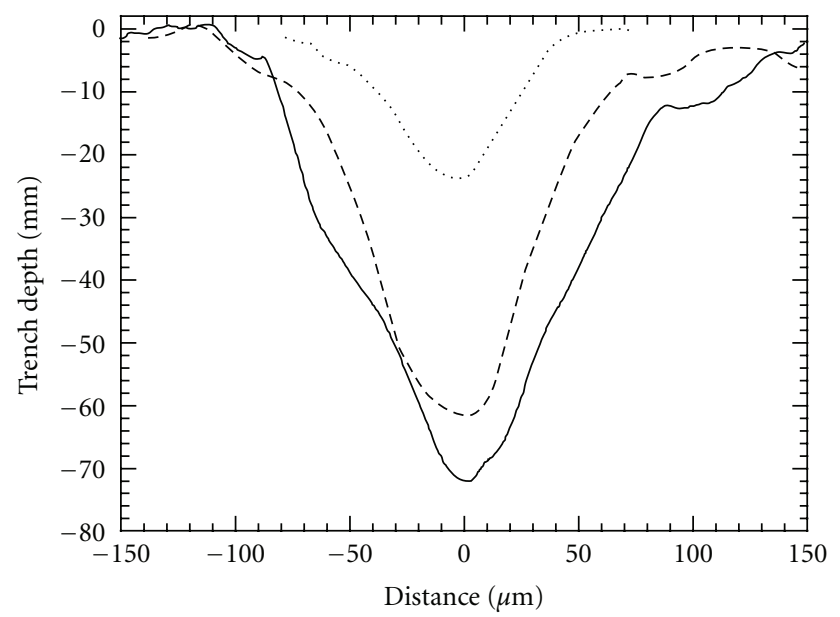

-.... 1320 hours

— 4098 hours

FIGURE 11: Selected trench profiles for neat epoxy samples at various stages of environmental degradation.

\section{Conclusion}

The influence of nanoscale clay reinforcement of epoxy on the resistance to environmental degradation was studied. An epoxy-clay nanocomposite was fabricated using Epon 862, a bisphenol F-based epoxy resin, cured using Epikure

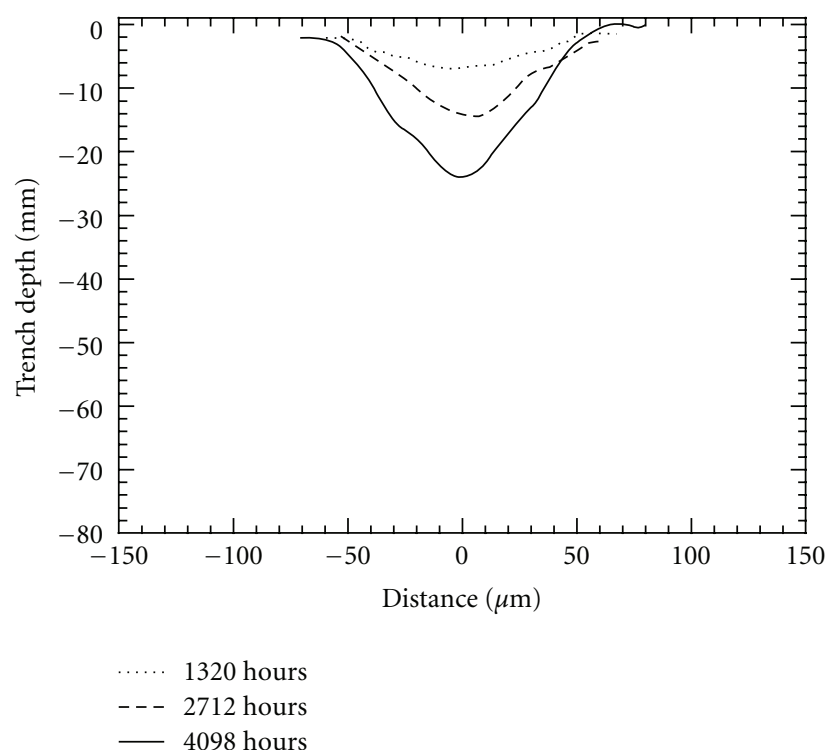

Figure 12: Selected trench profiles for epoxy-clay nanocomposite samples at various stages of environmental degradation.

3274, a moderately reactive aliphatic amine, and reinforced with 4 vol.\% of Nanomer I.30E, an organically modified clay. The clay particles were mixed and exfoliated with extensive mechanical mixing for 14 hours followed by high-shear dispersion for 30 minutes. Various mixing techniques were evaluated, and the selected process resulted in the greatest 


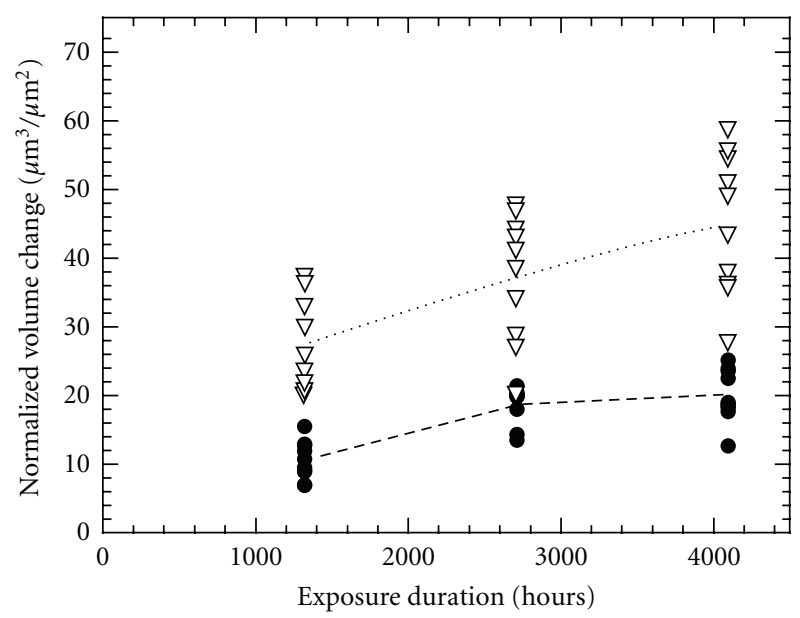

- Epoxy-clay nanocomposite

$\nabla \quad$ Neat epoxy

- - - Epoxy-clay nanocomposite (average trend) Neat epoxy (average trend)

Figure 13: Change in material volume, normalized with respect to the viewing area, as a function of exposure duration for neat epoxy and epoxy-clay samples exposed to combined UV radiation and condensation.

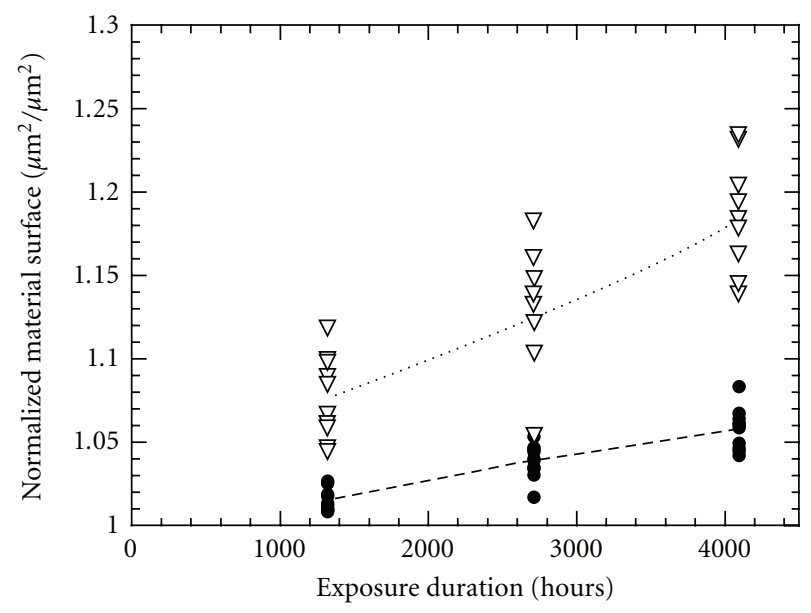

- Epoxy-clay nanocomposite

$\nabla \quad$ Neat epoxy

- - - Epoxy-clay nanocomposite (average trend)

..... Neat epoxy (average trend)

FIGURE 14: Change in material volume, normalized with respect to the viewing area, as a function of exposure duration for neat epoxy and epoxy-clay samples exposed to combined UV radiation and condensation.

improvement in mechanical properties indicating complete, or near complete, exfoliation of the clay platelets.

The nanocomposites were subjected to two environmental conditions, namely, combined UV radiation and condensation on a three-hour repeat cycle and constant relative humidity. Both types of exposures were conducted for 4770 hours and at fixed temperatures of $50^{\circ} \mathrm{C}$.
The variation of mass loss or gain was recorded to serve as an indicator of material degradation or moisture uptake. Batches of samples were removed after 1320, 2712 and 4098 hours to test for flexure modulus and strength using fourpoint bend testing.

Under the exposure of constant relative humidity it was found that both neat epoxy and the epoxy-clay nanocomposite gained mass. However, the presence of nanoscale reinforcements in the epoxy matrix acted as a barrier and significantly hindered the moisture absorption. As the result, the final moisture uptake value and the rate of the moisture uptake were both measurably reduced, as expected, in comparison to neat epoxy also reduced in epoxy-clay nanocomposites.

The combined exposure of UV radiation and condensation resulted in the loss of mass of both materials due to the erosion of epoxy by a synergistic physicochemical process that was previously identified and characterized by Kumar et al. [6]. They suggested the formation of photo-oxidative byproducts that underwent dissolution by water vapor condensation and run-off results in the removal of surface layers degraded by UV radiation. Therefore, cyclic exposure to both UV radiation and water vapor condensation results in a continual material degradation and erosion process. Recently, Woo et al. also suggested that the presence of moisture can enhance the mobility of free radicals and ions and, thereby, enhance the photo-oxidative effects of UV radiation $[33,34]$.

In the present study the epoxy-clay specimens exhibited greater mass loss as compared to neat epoxy, which was surprising. The variation of the mass was governed by two competing mechanisms, namely, decrease in mass due to loss of epoxy and increase in mass due to moisture absorption. It was hypothesized, and later confirmed, that the increased mass loss for epoxy-clay nanocomposites is due to decreased uptake of moisture and not increased erosion of the epoxy matrix. This was in accordance with the measurements of flexure modulus and strength after exposure to the two environments as a function of exposure duration. Exposure to relative humidity did not result in a measurable decrease in modulus for either neat epoxy or the epoxy-clay nanocomposite. For exposure to UV radiation and condensation the flexure modulus decreased for both materials with increasing exposure duration. This modulus decrease was due to epoxy erosion resulting from synergistic material degradation. Nonetheless, the decrease in modulus was greater for the neat epoxy specimens as compared to the epoxy-clay nanocomposite, which demonstrated that the addition of nanoscale clay is effective in enhancing resistance to moisture degradation.

The investigation into the flexure strength revealed that both materials underwent degradation in strength when exposed to either environment. The decrease in flexural strength was especially severe for exposure to combined UV radiation and condensation. This decrease in the flexure strength is primary due to surface erosion and formation of channels on the material surface. The channels originate as microcracks from UV exposure and then grow and deepen 
upon material erosion due to synergistic degradation. Nevertheless, the decrease in flexural strength was lower for the epoxy-clay nanocomposite, again leading to the conclusion that the addition of clay particles leads to enhancement in the resistance to environmental degradation. A comparison of the normalized flexure strength showed that the epoxyclay nanocomposite had retained $\sim 37 \%$ more strength than the neat epoxy after 4072 hours of exposure to combined UV radiation and condensation. Under exposure to constant relative humidity, however, the neat epoxy specimens retained greater strength.

High resolution imaging was used to quantify material volume and surface change due to environmental degradation. The change in material volume due to synergistic erosion was representative of overall material loss. On the other hand, the change in material surface was indicative of surface roughening due to the growth of trenches (or channels) on the specimen surface. The presence of clay reduced the formation and growth of channels from UV radiation-induced microcracking and subsequent erosion during combined exposure to UV radiation and condensation. These surface channels acted as defects and lowered the flexural strength. Therefore, a reduction in channel formation and growth, due to the presence of clay, led to greater strength retention. The formation and growth of these channels were identified as being more deleterious than overall material volume loss. This is also why the exposure to $\mathrm{UV}$ radiation and condensation led to a greater loss of flexural strength rather than modulus.

This investigation demonstrated that the nanoscale clay reinforcements in an epoxy matrix act as barriers to environmental degradation. The clay particles provide resistance to moisture transport. Nevertheless, the moisture absorption process in polymer clay nanocomposites is governed by numerous factors, including the cross linking density around the clay layers, degree of net cure, and the total exposed surface area of the clay platelets $[28,29]$. In addition, the interaction between UV exposure, moisture, and epoxy-clay chemistry is driven by complex physicochemical mechanisms. Therefore, further investigation is warranted to analyze the chemical and microstructural characteristics of the degradation process and establish the process kinetics in polymer nanocomposites subjected to varied environments.

\section{Acknowledgement}

The authors gratefully acknowledge the support of the National Science Foundation via Grant no. CMS 0219250.

\section{References}

[1] G. Pritchard, Reinforced Plastics Durability, Woodhead Publishing, Cambridge, UK, 1998.

[2] J. W. Chin, T. Nguyen, and K. Aouadi, "Effects of environmental exposure on Fiber-Reinforced Plastic (FRP) materials used in construction," Journal of Composites Technology and Research, vol. 19, no. 4, pp. 205-213, 1997.
[3] B. Ranby and J. Rabek, Photodegradation, Photo-Oxidation and Photostabilization of Polymers, John Wiley \& Sons, London, UK, 1975.

[4] W. B. Liau and F. P. Tseng, "The effect of long-term ultraviolet light irradiation on polymer matrix composites," Polymer Composites, vol. 19, no. 4, pp. 440-445, 1998.

[5] K.-B. Shin, C.-G. Kim, C.-S. Hong, and H.-H. Lee, "Prediction of failure thermal cycles in graphite/epoxy composite materials under simulated low earth orbit environments," Composites Part B, vol. 31, no. 3, pp. 223-235, 2000.

[6] B. G. Kumar, R. P. Singh, and T. Nakamura, "Degradation of carbon fiber-reinforced epoxy composites by ultraviolet radiation and condensation," Journal of Composite Materials, vol. 36, no. 24, pp. 2713-2733, 2002.

[7] A. W. Signor, M. R. VanLandingham, and J. W. Chin, "Effects of ultraviolet radiation exposure on vinyl ester resins: characterization of chemical, physical and mechanical damage," Polymer Degradation and Stability, vol. 79, no. 2, pp. 359-368, 2003.

[8] C. Shen and G. S. Springer, "Moisture absorption and desorption of composite materials," Journal of Composite Materials, vol. 10, no. 1, pp. 2-20, 1976.

[9] Y. Weitsman, Fatigue of Composite Materials, Elsevier, New York, NY, USA, 1991.

[10] Q. Zheng and R. J. Morgan, "Synergisitc thermal-moisture damage mechanisms of epoxies and their carbon fiber composites," Journal of Composite Materials, vol. 27, no. 15, pp. 1465-14789, 1993.

[11] R. D. Adams and M. M. Singh, "The dynamic properties of fibre-reinforced polymers exposed to hot, wet conditions," Composites Science and Technology, vol. 56, no. 8, pp. 977-997, 1996.

[12] H. S. Choi, K. J. Ahn, J.-D. Nam, and H. J. Chun, "Hygroscopic aspects of epoxy/carbon fiber composite laminates in aircraft environments," Composites Part A, vol. 32, no. 5, pp. 709-720, 2001.

[13] C. Soutis and D. Turkmen, "Moisture and temperature effects of the compressive failure of CFRP unidirectional laminates," Journal of Composite Materials, vol. 31, no. 8, pp. 832-849, 1997.

[14] G. Sala, "Composite degradation due to fluid absorption," Composites Part B, vol. 31, no. 5, pp. 357-373, 2000.

[15] G. Mago, F. T. Fisher, and D. M. Kalyon, "Effects of multiwalled carbon nanotubes on the shear-induced crystallization behavior of poly(butylene terephthalate)," Macromolecules, vol. 41, no. 21, pp. 8103-8113, 2008.

[16] E. T. Thostenson, C. Li, and T.-W. Chou, "Nanocomposites in context," Composites Science and Technology, vol. 65, no. 3-4, pp. 491-516, 2005.

[17] R. A. Vaia and E. P. Giannelis, "Polymer nanocomposites: status and opportunities," MRS Bulletin, vol. 26, no. 5, pp. 394-401, 2001.

[18] T. Pinnavaia, T. Lan, Z. Wang, H. Shi, and P. D. Kaviratna, Nanotechnology, vol. 622 of ACS Symposium Series, American Chemical Society, Washington, DC, USA, 1996.

[19] R. Krishnamoorti and R. A. Vaia, "Polymer nanocomposites: synthesis, characterization, and modeling," in Proceedings of the 219th National Meeting of the American Chemical Society, San Francisco, Calif, USA, 2000.

[20] A. Usuki, Y. Kojima, M. Kawasumi, A. Okada, T. Kurauchi, and O. Kamigaito, "Characterization and properties of nylon 6. Clay hybrid," in Proceedings of the ACS Division of Polymer Chemistry Meeting, pp. 651-652, Washington, DC, USA, August 1990. 
[21] M. Alexandre and P. Dubois, "Polymer-layered silicate nanocomposites: preparation, properties and uses of a new class of materials," Materials Science and Engineering $R$, vol. 28, no. 1, pp. 1-63, 2000.

[22] O. Becker, R. Varley, and G. Simon, "Morphology, thermal relaxations and mechanical properties of layered silicate nanocomposites based upon high-functionality epoxy resins," Polymer, vol. 43, no. 16, pp. 4365-4373, 2002.

[23] D. Ratna, N. R. Manoj, R. Varley, R. K. Singh Raman, and G. P. Simon, "Clay-reinforced epoxy nanocomposites," Polymer International, vol. 52, no. 9, pp. 1403-1407, 2003.

[24] S. C. Zunjarrao, R. Sriraman, and R. P. Singh, "Effect of processing parameters and clay volume fraction on the mechanical properties of epoxy-clay nanocomposites," Journal of Materials Science, vol. 41, no. 8, pp. 2219-2228, 2006.

[25] T. Ogasawara, Y. Ishida, and T. Ishikawa, "Helium gas permeability of montmorillonite dispersed nanocomposites," in Proceedings of the 11th US-Japan Conference on Composite Materials, Yamagata, Japan, 2004.

[26] Y. Kojima, A. Usuki, M. Kawasumi, A. Okada, T. Kurauchi, and O. Kamigaito, "Sorption of water in nylon 6-clay hybrid," Journal of Applied Polymer Science, vol. 49, no. 7, pp. 12591264, 1993.

[27] T. Lan and T. J. Pinnavaia, "Clay-reinforced epoxy nanocomposites," Chemistry of Materials, vol. 6, no. 12, pp. 2216-2219, 1994.

[28] T. Hwang, L. Pu, S. W. Kim, Y.-S. Oh, and J.-D. Nam, "Synthesis and barrier properties of poly(vinylidene chlorideco-acrylonitrile) $/ \mathrm{SiO}_{2}$ hybrid composites by sol-gel process," Journal of Membrane Science, vol. 345, no. 1-2, pp. 90-96, 2009.

[29] J.-K. Kim, C. Hu, R. S. C. Woo, and M.-L. Sham, "Moisture barrier characteristics of organoclay-epoxy nanocomposites," Composites Science and Technology, vol. 65, no. 5, pp. 805-813, 2005.

[30] "Standard test method for flexural properties of unreinforced and reinforced plastics and electrical insulating materials by four-point bending," ASTM D6272-10, American Society for Testing and Materials, 2010.

[31] "Standard test methods for plane-strain fracture toughness and strain energy release rate of plastic materials," ASTM D5045, American Society for Testing and Materials, 1999.

[32] T. L. Anderson, "Fracture mechanics: fundamentals and applications," CRC Press 2004.

[33] R. S. C. Woo, Y. Chen, H. Zhu, J. Li, J.-K. Kim, and C. K. Y. Leung, "Environmental degradation of epoxyorganoclay nanocomposites due to UV exposure. Part I: photo-degradation," Composites Science and Technology, vol. 67, no. 15-16, pp. 3448-3456, 2007.

[34] R. S. C. Woo, H. Zhu, C. K. Y. Leung, and J.-K. Kim, "Environmental degradation of epoxy-organoclay nanocomposites due to UV exposure. Part II: residual mechanical properties," Composites Science and Technology, vol. 68, no. 9, pp. 21492155, 2008. 

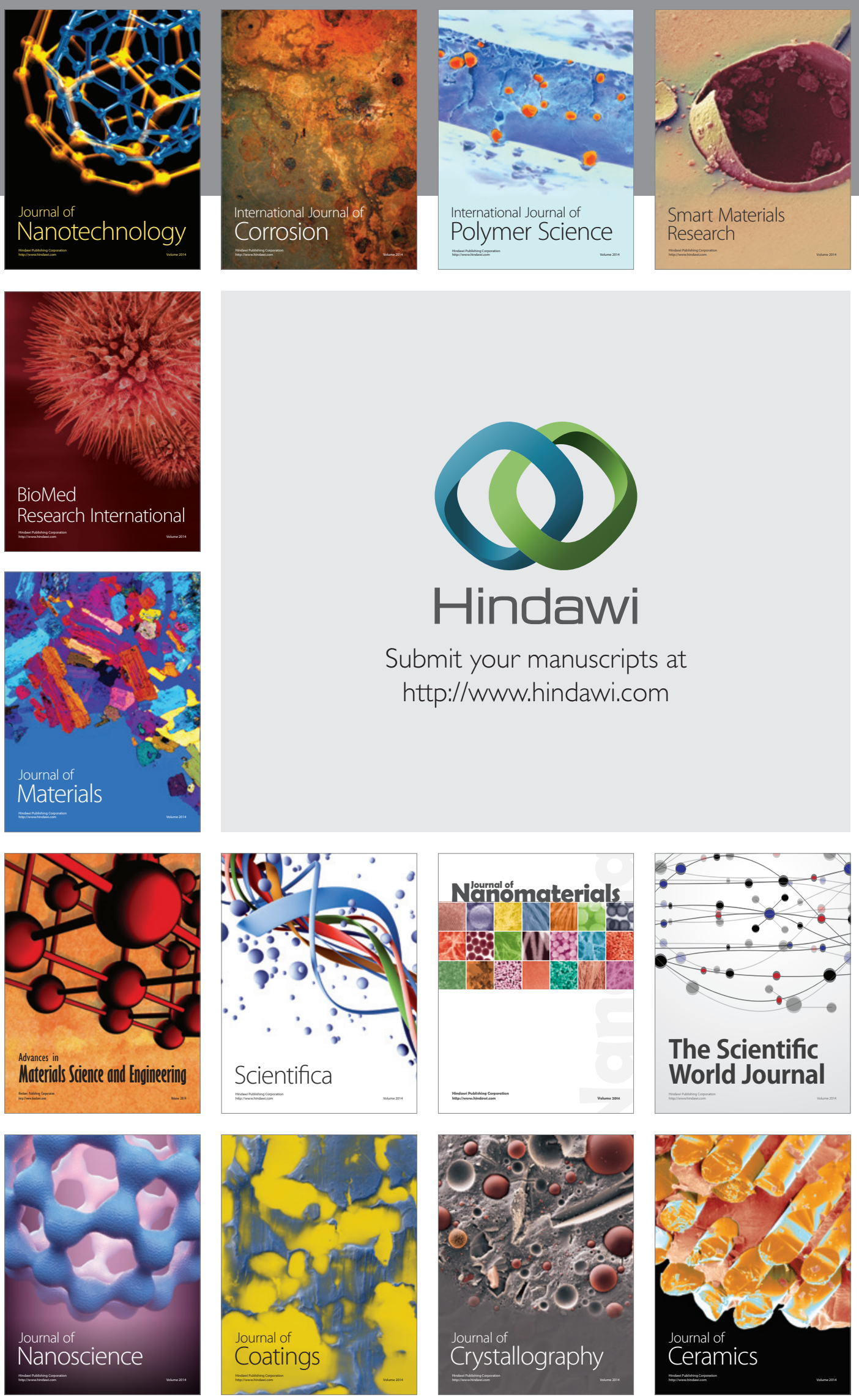

The Scientific World Journal

Submit your manuscripts at

http://www.hindawi.com

\section{World Journal}

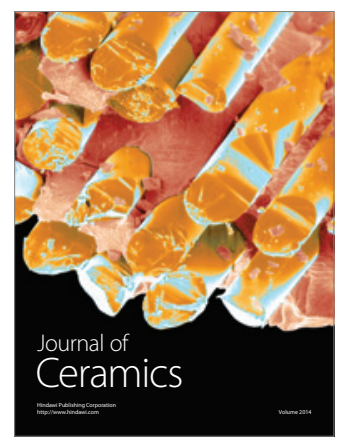

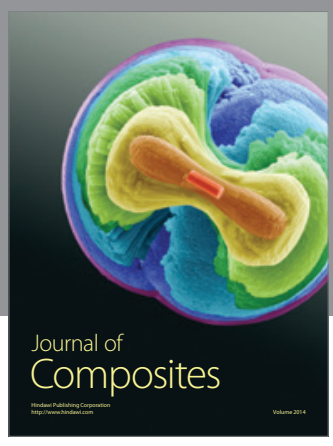
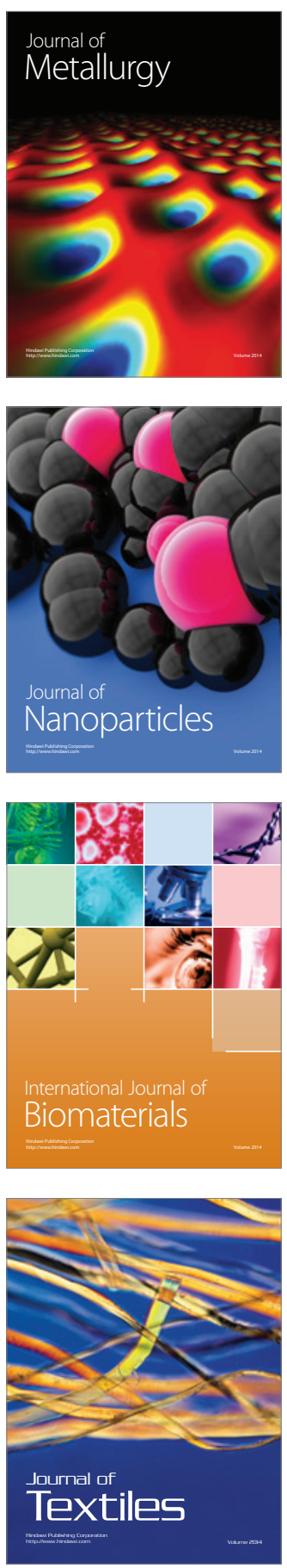